\title{
Superiority of the Rapid Von Willebrand Factor (VWF) VWF:GPIbR and VWF:GPIbM Assays in Type 2A, 2B and 2M Von Willebrand Disease
}

\author{
Jan Jacques Michiels ${ }^{1,2}$, Petr Smejkal ${ }^{1}$, Katarzina Mayger ${ }^{3}$, Gary Moore ${ }^{3}$, Jan Blatny ${ }^{4}$, \\ Miroslav Penka $^{1}$, Ulrich Budde ${ }^{5}$, Zwi Berneman ${ }^{6}$, Inge Vangenechten ${ }^{6}$, Alain Gadisseur \\ ${ }^{1}$ Department of Clinical Hematology, University Hospital and Department of Laboratory Methods, Faculty of Medicine, Masaryk University \\ Brno, Brno, Czech Republic \\ ${ }^{2}$ Goodheart Institute in Nature Medicine \& Health, Blood Coagulation and Vascular Medicine Center, Freedom of Science, Art and \\ Education, European Free University Network, Rotterdam, The Netherlands \\ ${ }^{3}$ Department of Haemostsis \& Thrombosis, Viapath Analytics at Guy's \& St Thomas' NHS Foundation Trust, London, UK \\ ${ }^{4}$ Department of Pediatric Hematology, Center for Thrombosis and Hemostasis, Children's University Hospital, Brno, Czech Republic \\ ${ }^{5}$ Central Laboratory, Asklepios Kliniken, Hamburg, Germany \\ ${ }^{6}$ Department of Hematology and Hemostase Research Unit, University Hospital Antwerp, Edegem, Belgium
}

\section{Email address:}

j.michiels23@upcmail.nl (J. J. Michiels), goodheartcenter@outlook.com (J. J. Michiels), smejkal.petr@fnbrno.cz (P. Smejkal), kasia.mayger@viapath.co.uk (K. Mayger), gary.moore@viapath.co.uk (G. Moore), blatny.jan@fnbrno.cz (J. Blatny), penka.miroslav@fnbrno.cz (M. Penka), u.budde@asklepios.com (U. Budde),Zwi.Berneman@uza.be (Z. Berneman), inge.vangenechten@uza.be (I. Vangenechten), Alain.gadisseur@uza.be (A. Gadisseur)

\section{To cite this article:}

Jan Jacques Michiels, Petr Smejkal, Katarzina Mayger, Gary Moore, Jan Blatny, Miroslav Penka, Ulrich Budde, Zwi Berneman, Inge Vangenechten, Alain Gadisseur. Superiority of the Rapid von Willebrand Factor (VWF) VWF:GPIbR and VWF:GPIbM Assays in Von Willebrand Disease Type 2A, 2B and 2M. International Journal of Clinical and Experimental Medical Sciences.

Vol. 5, No. 5, 2019, pp. 80-91. doi: 10.11648/j.jicems.20190505.14

Received: July 9, 2019; Accepted: August 30, 2019; Published: October 23, 2019

\begin{abstract}
A complete set of rapid activity and classical von Willebrand factor (VWF) assays for Willebrand disease (VWD) diagnosis was used in the present study to characterize VWD type 1,2A, 2B and $2 \mathrm{M}$ patients due to mutations in the $\mathrm{A} 1, \mathrm{~A} 2$ and A3 domains. The VWF:RCo/VWF:Ag, VWF:GPIbM/VWF:Ag and VWF:GPIbR/VWF:Ag ratios at cuttt off value of 0.7 separated VWD type 1 and LowVWF from VWD type 2. The results from the Brno cohort of VWD 2A patients with the G1579R mutation in the A2 domain in sixteen affected member from five families and in one case with the G1609R in the A2 domain revealed that the VWF:GPIbM/VWF:Ag and VWF:GPIbR/VWF: Ag ratios are marked decreased (range 0.03-0.27) to a similar degree as compared to VWF:RCo/VWF:Ag and VWF:CB/VWF:Ag ratios (range 0.03-0.27) due to the proteolytic loss of large and intermediate VWF multimers. The results in VWD 2B patients due to gain of ristocetin induced platelet agglutination (RIPA) function mutations R1306W, R1308C and R1341 in the A1 domain demonstrated that the ratios for VWF:GPIbM/VWF:Ag and VWF:GPIbR/VWF:Ag as compared to VWF:RCo/VWF:Ag ratio were markedly decreased in VWD 2B, whereas the VWF:GPIbM/VWF:Ag ratio was somewhat higher (range 0.32 to 0.36) in VWD 2M. VWD 2M patients due to loss of RIPA function mutation R1359K in the A1 domain are featured by decreased VWF ratios for WVF:RCo/Ag and VWF:GPIbR/Ag, but less decreased for the VWF:GPIbM/Ag ratio and normal VWF ratio for VWF:CB/Ag ratio the need to retain the VWF:CB assay to make a correct diagnosis of VWD 2M for its differentiation from VWD type 1. The G1415D mutation in the A1 domain is featured by decreased RIPA and decreased VWF:RCo/VWF:Ag ratio (VWD 2M) but normal values for VWF:CB/VWF:Ag, VWF:GPIbM/VWF:Ag and VWFGPIbR/VWF:Ag ratios consistent with VWD 2M. Double heterozygous P1266L/V1278I mutation in two patients and heterozygous E1292D/WT mutation in three patients in the A1 domain were diagnosed as VWD 2M or $1 \mathrm{M}$ associated with a secretion defect (SD). The Platelet Function Analyzer Closure Times (PFA-CT) are strongly prolonged in VWD $2 \mathrm{~A}, 2 \mathrm{~B}$ and $2 \mathrm{M}$. and moderately prolonged between the upper limit of normal to 300 seconds in heterozygous mutated VWD type 1 patients.
\end{abstract}


Keywords: Von Willebrand Disease, Von Willebrand Factor, VWF Acitivity, VWF Propeptide,

Ristocetine Induced Platelet Agglutination RIPA, VWF Domain, Platelet Function Analyser,

VWD Classification

\section{Introduction}

The classification of von Willebrand disease (VWD) by the International Society on Thrombosis and Haemostasis (ISTH) started with the discovery of Ruggeri in 1980 of heightened interaction of ristocetin induced platelet aggregation (RIPA) and functional abnormal von Willebrand factor (VWF) protein in the presence of ristocetine in dominant VWD type IIB (2B), and RIPA is decreased or absent in dominant VWD dominant IIA (2A) [1-7]. The Antwerp classification of VWD [1-3] clearly defined the VWF laboratory, multimer and molecular defects of VWD type 1 and variants of type dominant VWD type 2 into $2 \mathrm{~A}$ and 2B (Figure 1) as the improved extension of the ISTH classification [1]. VWD 2B differs from 2A by increased RIPA in VWD 2B. Pronounced increase of degraded proteolytic band and triplet structure of each VWF band is the hall mark of VWD type 2A due to mutations in the A2 domain and caused by proteolysis of VWF at the VWF cleavage site (1605-1606) arising from hypersensitivity of VWF to cleavage protease ADAMTS13 [1-9]. The RIPA gain of function mutations in the A1 domain in VWD 2B in vivo result in increased VWF-GPIb-platelet interaction followed by proteolysis of large VWF multimers at the VWF cleavage site with an increase of proteolytic band and triplet structure of each VWF band similar as seen in VWD 2A [19]. The laboratory phenotypes of VWF parameters in VWD type $2 \mathrm{~A}$ and $2 \mathrm{~B}$ are similar characterized by prolonged $\mathrm{BT}$, consistently low VWF ratios for VWF:RCo/Ag and VWF:CB/Ag, absence of high and some of the intermediate VWF multimers with pronounced triple structure of individual VWF bands, and increased VWF degradation products (Figure 1). RIPA is normal in mild VWD 2A and decreased RIPA in moderate and severe VWD 2A respectively [1-7]. In VWD 2B due to gain of RIPA function mutation in the A1 domain the mutated $2 \mathrm{~B}$ VWF protein spontaneously interact with the platelet GPIb receptor, which in vivo is followed by increased proteolysis of large VWF multimers at the VWF cleavage site 1605-1606 in the A2 domain similar as in VWD 2A [1-7]. Patients with severe VWD $2 \mathrm{~B}$ respond to DDAVP with thrombocytopenia due to heightened interaction of $2 \mathrm{~B}$ mutated VWF protein and platelet GPIb receptor, which result in in vivo platelet aggregates and clumps followed by proteolysis of mutated VWF at the VWF cleavage site in the A2 domain. Patients with mild 2B VWD including VWD Malmo and New York (mutation 1266) have increased RIPA, normal VWF multimers and respond to DDAVP with absence of transient thrombocytopenia $[1,2]$. VWD $2 \mathrm{M}$ is due to loss of VWF GPIb function mutation in the A1 domain and presents with the combination of decreased VWF:RCo/VWF:Ag ratio, decreased RIPA, the presence of near normal, normal or smeary VWF multimers, poor response to DDAVP of VWF:RCo as compared to fairly good responses of VWF:Ag, VWF:CB and FVIII:C to DDAVP.

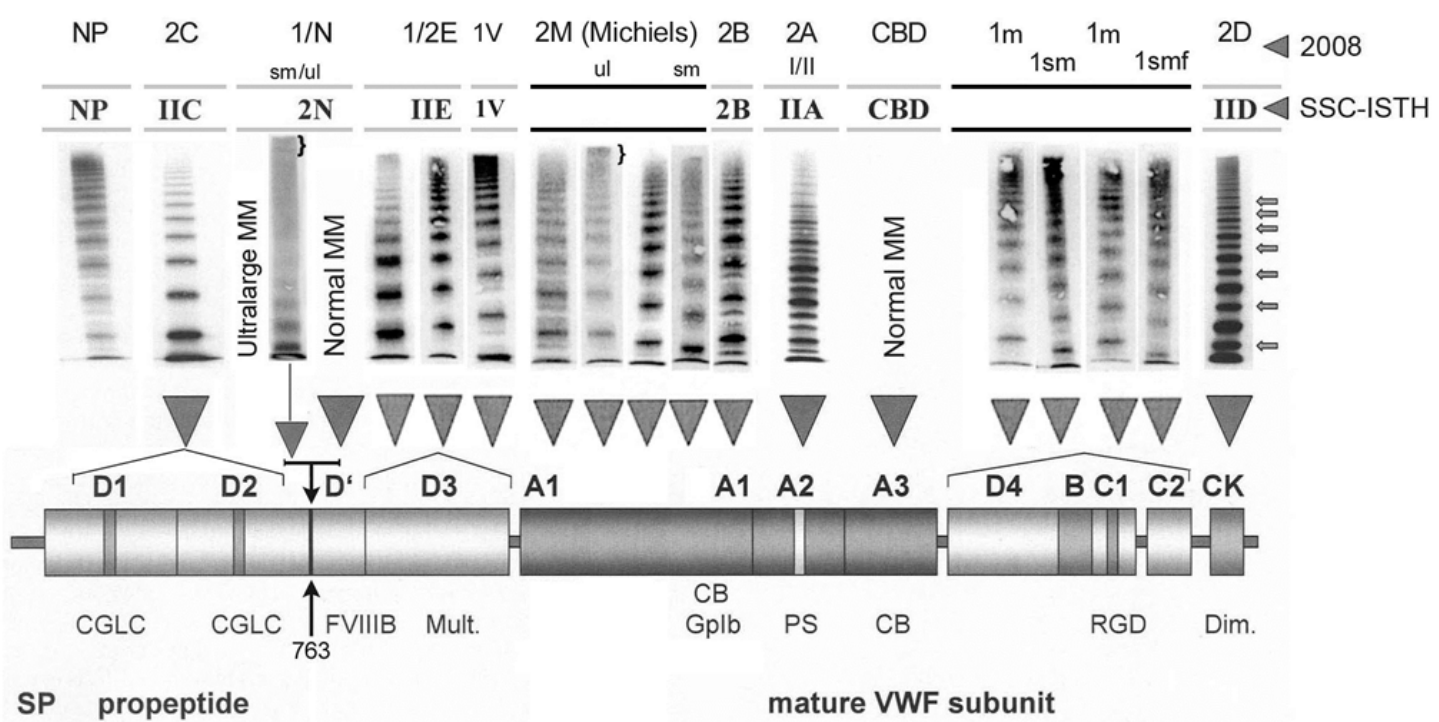

Figure 1. Translation of the ISTH Classification into the 2008 Antwerp Classification of von Willebrand Disease type 2A, 2B, 2C, 2D, $1 / 2 E$, Collagen Binding Defect $(C B C)$ and type 1 smeary multimers (smf) using von Willebrand factor (VWF) multimer analysis related to domain location of mutations in the VWF gene. Designed by Michiels \& Gadisseur 2008 [1-7].

In previous reports Vangenechten et al directly compared the performances of the rapid VWF:GPIbM (INNOVANCE) assay in the absence of ristocetin versus the rapid VWF:GPIbR (HemosIL) assay in the presence of ristocetin 
against the classical VWF:RCo assay in ISTH defined patients from the Brno cohort of 204 cases with suspected VWD $[8,9]$. As the rapid VWF GPIbR assay is quite similar as the classical VWF:RCo assay the introduction of the VWF:GPIbR to replace the VWF:RCo assay will not essentially change the concept and may even strenghten of the ISTH classification. The rapid VWF:GPIbR is affected by the clinically insignificant D1472H and P1476S single nucleotide polymorphisms (SNPs) in the A1 domain in a similar way as the insensitive classical VWF:RCo assay, whereas the VWF:GPIbM will not be influenced by D1472H and P1476S snips as dysfunctional. We here predict similar results of both VWF:GPIbR and VWF:GPIbM assays in VWD type 1 and $2 \mathrm{~A}$ due to mutations in the $\mathrm{A} 2$ and $\mathrm{A} 3$ domain but expect significant differences between the VWF:GPIbM vs VWF:GPIbR results in VWD 2B and 2M caused by gain or loss of RIPA function mutations in the A1 respectively. In the present study we investigated the performances of the rapid VWF:GPIbR and VWF:GPIbM assays against the classical VWF:RCo assay in European Clinical Laboratory and Molecular (ECLM 2018) defined VWD patients type $2 \mathrm{~A}, 2 \mathrm{~B}$ and $2 \mathrm{M}$ due to mutations in the $\mathrm{A} 1, \mathrm{~A} 2$ and $\mathrm{A} 3$ domain of the VWF gene. We addressed the question whether the VWF collagen binding (VWF:CB) ELISA assay is still needed for the differential diagnosis between VWD type $1 \mathrm{~m}$ or $1 \mathrm{sm}$ and VWD $2 \mathrm{M}$ and the

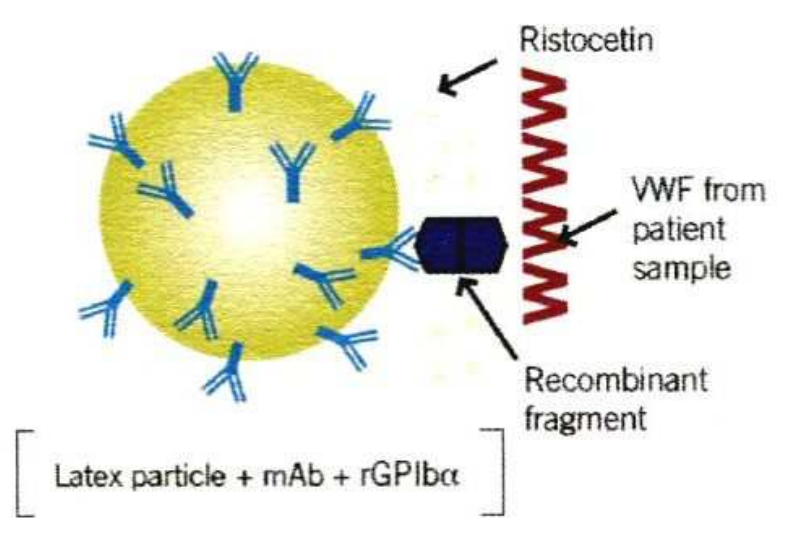

differentiation between VWD 2M versus VWD 2A and 2B.

\section{Principles of the Rapid VWF: GPIbR and VWF: GPIbM Assays}

The rapid VWF:GPIbM (INNOVANCE) on a Sysmex CS2000i analyser (Sysmex UK, Milton Keynes, UK) utilizes a recombinant GPIb $\alpha$ fragment containing two gain-offunction mutations $\mathrm{G} 233 \mathrm{~V}$ and $\mathrm{M} 238 \mathrm{~V}$ in Glycoprotein $\mathrm{Ib}$ (GPIb) from patients with Platelet 2B VWD. The G233V and M238 mutants spontaneously bind to the GPIb receptor on the A1 domain of plasma VWF in the absence of ristocetin $[10,11]$. Added microparticles coated with an antibody against GPIb $\alpha$ will bind the VWF-recombinant GPIb $\alpha$ complex inducing microparticle agglutination and subsequent decrease in light transmission which is directly proportional to the VWF GPIb-binding activity in the plasma (Figure 2) [8-11]. The gain of function mutations introduced into the GPIb fragments are known from the platelet type VWD 2B, which is characterized by spontaneous binding of plasma VWF to platelets with mutant GPIb receptor, hence there being no requirement for ristocetin $[8,9]$. These mutations play an important role in the binding of platelet GPIb ligand to the GPIb receptor in the A1 domain of plasma VWF (Figure 2).

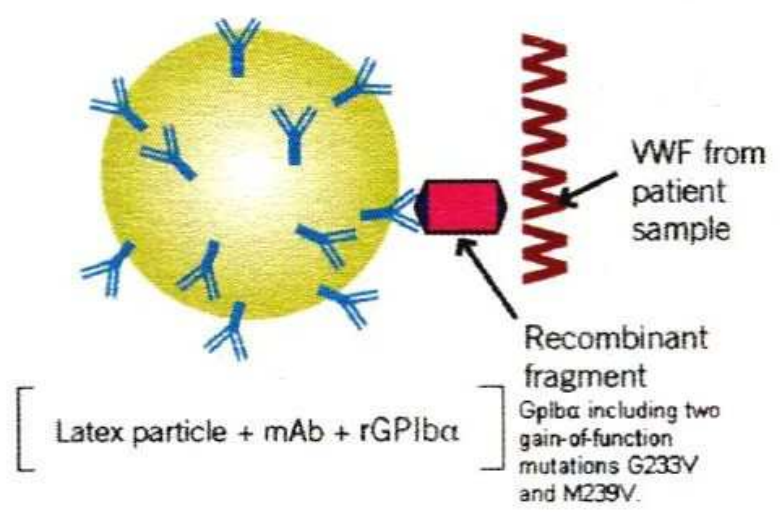

Figure 2. Assay principles of different von Willebrand Factor GPIb-binding activity kits [8-11]. Left: VWF: GPIbR (HemosIL - VWF:RCo Werfen) involves binding of plasma VWF to recombinant GPIb-antibody fragments attached to latex microparticles via monoclonal antibodies in the presence of ristocetin. Right: VWF:GPIbM (INNOVANCE), Siemens Healthcare Diagnostics) uses microparticles coated with an antibody against GPIb which bind recombinant GPIb-antibody containing two gain-of-function mutations (G223V, M239V) where no ristocetin is required for agglutination. Using all reagents platelets or GPIb-coated latex microparticles will spontaneously agglutinate is in proportion to the GPIb-binding activity of VWF in the sample and is determined by measuring the decrease of light transmission caused by this agglutination [8, 9].

The rapid activity assay VWF:GPIbR (HemosIL) is based on reagent containing latex particles coated with GPIb on their surface which bind active VWF present in the plasma through its GPIb receptor in the presence of ristocetin. A VWF-platelet complex is formed by platelet agglutination which is proportional to the capacity of plasma VWF to bind platelets in the presence of ristocetin and is determined by measuring the decrease of light transmission caused by this agglutination (Figure 2) [8-10]. The classical VWF:RCo is based on reagent containing formalin-fixed platelets which bind active VWF in the presence of ristocetin in the aggregometer through binding of platelet GPIb ligand to the GPIb receptor in the A1 domain of plasma VWF $[8,9]$. In the present study dominant VWD type $2 \mathrm{E}, 2 \mathrm{~A}, 2 \mathrm{~B}, 2 \mathrm{M}$ and $2 \mathrm{CB}$ were classified according to European Clinical Laboratory and Molecular (2018 ECLM, Table 1) criteria of VWD [1-7]. 
Table 1. European Clinical Laboratory and Molecular (2018 ECLM) Classification of Von Willebrand.

\begin{tabular}{|c|c|}
\hline \multicolumn{2}{|c|}{ Low VWF type 1: VWF:Ag levels >0.30-0.60 U/mL. Normal VWF:CB/Ag and VWF:RCo/Ag ratio >0.70 } \\
\hline \multicolumn{2}{|c|}{ Type 3: VWF:Ag and FVIII:C undetectable or very VWF due double null VWF gene mutation. } \\
\hline \multicolumn{2}{|c|}{ Severe type 1 hemophilia A phenotype due to mutations in the D1 domain (manuscript in preparation) } \\
\hline \multicolumn{2}{|c|}{ Severe type 1 VWD VWF:Ag and VWF:RCo detectable, increased FVIII:C/VWF:Ag ratio due to secretion defect. } \\
\hline & Domain \\
\hline \multicolumn{2}{|l|}{ Recessive von Willebrand Disease: VWD } \\
\hline \multicolumn{2}{|l|}{ Recessive severe type 3 double null mutation VWF gene double null } \\
\hline Recessive severe or pronounced type 1 , homozygous or double missense & D1 D2 D’ D4 C1-C6 \\
\hline Recessive severe type 1 VWD-hemophilia A mimicking type 3 & D1 \\
\hline Recessive 2N FVIII:C/VWF:Ag ratio $<0.5$ due to FVIII-VWF binding defect & D'-D3 \\
\hline Recessive $2 \mathrm{C}$ FVIII:C/VWF:Ag ratio increased due to secretion multimerization defect & D2 \\
\hline Recessive severe $1 \mathrm{sm}$, dominant $1 \mathrm{~m}$ or $1 \mathrm{sm}$ with normal $(\mathrm{m})$ or smeary $(\mathrm{sm}) \mathrm{MM}$ & D4 C1-C6 \\
\hline \multicolumn{2}{|l|}{ Dominant von Willebrand Disease VWD } \\
\hline 2E: type $1 / 2$, loss of large multimers, no triplets and normal or increased clearance & D3 \\
\hline 2A: Loss of large MM, decreased VWF: $\mathrm{RCo} / \mathrm{Ag}$ and $\mathrm{CB} / \mathrm{Ag}$ ratio, $\mathrm{RIPA} \mathrm{N}$ or decreased & A2 \\
\hline 2M: Decreased RIPA and VWF:RCo/VWF:Ag ratio, normal VWF:CB/VWF:Ag ratio & A1 \\
\hline 2B: Loss of large MM, increased RIPA, decreased VWF ratio for $\mathrm{RCo} / \mathrm{Ag}$ and $\mathrm{CB} / \mathrm{Ag}$ & A1 \\
\hline 2CB Collagen binding defect, VWF:RCo/Ag ratio normal and $\mathrm{CB} / \mathrm{VWF}$ : $\mathrm{Ag}$ ratio $<0.7$ & A3 \\
\hline 2D: Dimerization defect, loss of large MM, intervening bands and absence of triplets & $\mathrm{CK}$ \\
\hline
\end{tabular}

\section{Normal Values of Rapid VWF Activity and VWF Antigen determinations}

In this study the rapid VWF:GPIbM (INNOVANCE) and the VWF:GPbR (HemosIL) assays were performed on a Sysmex CS2100 and VWF antigen (VWF:Ag) immunoassay was performed on the ACL TOP 500. These three VWF assays were used to generate reference values in 201 controls related to blood group O vs Non-O (Table 2, Unpublished Mayger \& Dr Moore). Blood group O vs non-O specific cut-offs, mean, median and reference intervals (RI) for the VWF:GPIbM activity assay and VWF:Ag in a large group of 201 healthy donors (Mayger et al ISTH poster 2015, Table 2). The results of the VWF:GPIbM and VWF:GPIbR assays are shown in Table 2. The lower limits of normal VWF:GPIbM and VWF:GPIbR are 0.32 and 0.45 in Blood group $O$ and 0.37 and 0.50 in Non-O blood group respectively. The reference intervals (RI) are lower in the VWF:GPIbM compared to VWF:GPIbR (difference 0.13). The reference interval (RI) of VWF:Ag assay are much higher as compared to VWF:GPIbM assay and somewhat less for VWF:GPIbR assay.

Table 2. Normal values of VWF:GPIbM and VWF:GPIbR assays in a large group of 183 healthy donors according to ABO blood group $O$ (N=95) and Non-O $(N=84)$ and O/Non-O (N=201) (Mayger and Dr Moore, ISTH Poster 2010).

\begin{tabular}{lllll}
\hline Donor population & & VWF:GPIbM & VWF:GP1bR & VWF:Ag \\
\hline Blood group & & IU/dL & IU/dL & IU/dL \\
\hline $\mathrm{O}$ & Mean & 0.71 & 0.77 & 0.87 \\
$\mathrm{~N}=95$ & Median & 0.67 & 0.72 & 0.83 \\
& RI & $0.32-1.05$ & $0.45-1.23$ & $0.53-1.27$ \\
$\mathrm{Non}-\mathrm{O}$ & Mean & 1.01 & 1.02 & 1.13 \\
$\mathrm{~N}-84$ & Median & 1.00 & 0.98 & 1.11 \\
& RI & $0.37-1.64$ & $0.50-1.54$ & $0.65-1.86$ \\
$\mathrm{O} /$ non-O & Mean & 0.85 & 0.89 & 0.99 \\
$\mathrm{~N}=201$ & Median & 0.80 & 0.87 & 0.94 \\
& RI & $0.38-1.65$ & $0.47-1.53$ & $0.53-1.70$ \\
\hline
\end{tabular}

The lower levels of VWF:GPIbM and VWF:GPIbR are 0.32 and 0.45 in Blood group O and 0.37 and 0.50 in Non-O blood group respectively. The reference intervals (RI) are much lower in the rapid VWF:GPIbM assay compared to the rapid VWF:GPIbR assay (difference 0.13). The reference interval (RI) of VWF:Ag assay are much higher as compared to VWF:GPIbM assay and somewhat less for VWF:GPIbR assay.

\section{Introduction of the VWF:GPIbM Assay by Patzke \& Budde, Germany}

The German study of Patzke \& Budde introduced the commercialized VWF:GPIbM (INNOVANCE) assay in 2014 using a large cohort of 153 VWD patients from the MCMDM-1VWD European study $[10,11]$ misclassified according to the ISTH-Schneppenheim/Budde criteria and reclassified by Michiels according to the Antwerp (Figure 1) and 2018 ECLM criteria (Table 1) [11]. The mutants C1130R, C1130G, W1144G, C1130G/R2263P, Y1146C/S1378F and R924Q/R1315L were diagnosed as 2A (IIE) 5 of them had 
VWF:RCo/VWF:Ag ratio below 0.7 (type $2 \mathrm{E}$ ) and 2 above 0.7 (type 1E) (Table 1). The A1 loss of RIPA function mutation L1307P (IB), R1315C (2A), and R1315H (IIE) were diagnosed as VWD $2 \mathrm{M}$ in the Antwerp and ECLM classification (Table 3) [11]. Out of 79 cases of VWD type 1, three had VWF activity / VWF antigen ratios below 0.70 in the VWF:GPIbM and VWF:RCo assays (Table 3). Out of 32 ISTH defined IIA VWD lumping ECLM defined 2A, 2C, 2E cases had normal antigen/activity ratios in both assays normal in 7 , discrepant in 3 , and below 0.7 in both assays in 6. The broad range of VWF: Ag and all VWF functional parameters in 32 VWD 2A (IIA plus IIE) from very low to normal in Table 3 is due to lumping VWD IIA and IIE as 2A in the ISTH classification. Twenty-four cases of VWD 2B and 3 cases of VWD 2M were diagnosed as type 2 (Table 3 ). All nine cases of $2 \mathrm{Msm}=$ type 1 were correctly diagnosed as VWD type $1 \mathrm{sm}$ (Table 2). The overall conclusion is that the performances of the VWF:GPIbM and VWF:RCo assays in terms of activity ratios are identical in VWD type $1,2 \mathrm{~B}, 2 \mathrm{M}$, and type $2 \mathrm{Msnf}=$ type 1 , but that the VWF:GPIbM/VWF:Ag ratio in VWD $2 \mathrm{~B}$ is significantly lower as compared to the VWF:RCo/VWF:Ag ratio (Table 3) [10, 11].

Table 3. Direct comparison of the classical VWF:RCo activity assay and the rapid VWF:GPIbM (INNOVANCE) activity assay in the German study of Patzke et al [10] in VWD patients reclassified according to the ECLM classification analysed by Michiels et al [11].

\begin{tabular}{|c|c|c|c|c|c|c|}
\hline ISTH-ECLM & Type 1 ISTH-ECLM & IIA-2A IIE-2E & 2B-2B & $2 M-2 M$ & 1- $1 \mathrm{sm}$ & $2 \mathrm{~N}-2 \mathrm{~N}$ \\
\hline Number of patients & 79 & 32 & 24 & 3 & 9 & 6 \\
\hline VW:Ag \% & 51 & 44 & 52 & 50 & 72 & 87 \\
\hline range & $12-84$ & $9-119$ & $28-107$ & $18-81$ & $22-201$ & $51-139$ \\
\hline VWF:RCo \% & 39 & 25 & 18 & 21 & 72 & 74 \\
\hline range & $10-71$ & $10-95$ & $10-73$ & $12-32$ & $16-172$ & $38-117$ \\
\hline VWF:GPIbM \% & 38 & 25 & 14 & 21 & 72 & 79 \\
\hline range & $4-72$ & 4-111 & $4-47$ & $8-35$ & $22-176$ & $44-125$ \\
\hline VWF RCo/Ag & 0.84 & 0.60 & 0.36 & 0.48 & 0.99 & 0.89 \\
\hline range & $0.46-1.35$ & $0.16-1.20$ & $0.17-0.68$ & $0.39-0.66$ & $0.74-1.24$ & $0.53-1.04$ \\
\hline \multicolumn{7}{|l|}{ Ratio } \\
\hline VWF:GPIbM/Ag & 0.80 & 0.56 & 0.26 & 0.43 & 1.00 & 0.93 \\
\hline range & $0.39-1.119$ & $0.13-1.15$ & $0.12-0.50$ & $0.40-0.44$ & $0.88-1.18$ & $0.61-1.05$ \\
\hline
\end{tabular}

The broad range of VWF:Ag and all VWF functional parameters in VWD 2A from very low to normal in Table 3 is due to lumping VWD IIA (2A ECLM) and IIE (2E ECLM) in ISTH defined VWD 2A including ISTH defined IIA, IIE, IICand IID. The VWF:GPIbM values and the VWF:GPIbM/VWF:Ag ratios in VWD 2B are lower than the corresponding VWF:RCo/VWF:Ag ratios, but equal in VWD 2M indicating the need to retain RIPA and VWF: CB-I-III to correctly differentiate between VWD 2B and 2M.

\section{VWF:GPIbR and VWF:GPIbM Results in VWD 2A, 2B and 2M}

VWD $2 A$ due to mutations in the A2 domain

The results in sixteen cases of G1579R mutated VWD type 2A from five families the rapid VWF:GPIbM (0.04-0.12) vs VWF:GPIbR (0.03-0.20 U/dL) assays are very low and do not differ (Tables 4 and 5). The results of the two novel rapid VWF activity assays VWF:GPIbM and VWF:GPIbR are significantly lower than the decreased values for the classical assay VWF:RCo (0.04-0.28 U/dL) and VWF:CB (0.11-0.30 $\mathrm{U} / \mathrm{dL}$ ) in sixteen cases of G1579R mutated VWD type $2 \mathrm{~A}$ from five families (Tables 4 and 5). VWF multimeric analysis in G1579R mutated VWD 2A patients showed the lack of large and intermediate VWF multimers and a triple stucture of each VWF band in the medium resolution gel (Figure 3). Much lower values of VWF:GPIbM/VWF:Ag and VWF:GPIbR/VWF:Ag ratios (0.03 to 0.27$)$ as compared to VWF:RCo/VWF:Ag and VWF:CB/VWF:Ag ratios (0.060.53 ) were recorded in sixteen G1579R mutated VWD $2 \mathrm{~A}$ patients and in one G1609R/WT mutated VWD 2A patient (Table 4). The high sensitivity of the novel rapid VWF: GPIbM and VWF: GPIbR assays as compared to the classical VWF: RCo assay in G1579R mutated VWD 2A is related to the absence of all large and some of the intermediate VWF multimers (Figure 3).

The ratios between VWF propeptide (VWF:pp) and VWF:Ag in the affected sixteen cases of G1579R mutated VWD 2A are slightly increased with VWFpp/VWF:Ag ratios from 1.11 and 2.15 not meeting the criterion for a clearance (C) defect (VWFpp/VWF:Ag ratio >2.0) [5]. Similar findings of slightly increased VWFpp/VWF:Ag ratios has been reported in 10 affected patients in a large Dutch family with dominant VWD 2A Gouda due to the V1499E mutation [12].

VWD type 1 due to mutation Y1584C in the A2 domain

VWD type 1 due to mutation Y1584C in the A2 domain. All seven patients heterozygous for the Y1584C/WT mutation were diagnosed as VWD $1 \mathrm{~m}$ (normal VWF multimers) (Table 6). Double heterozygosity for the A2/D1 domain mutation $\mathrm{Y} 1584 \mathrm{C} / \mathrm{G} 39 \mathrm{R}$ in two cases and A2/D' domain mutation $\mathrm{Y} 1584 \mathrm{C} / \mathrm{P} 812 \mathrm{rfs}$ in 1 case resulted in severe VWD type 1 secretion defect (SD) with increased FVIII/VWF:Ag ratio with strongly prolonged PFA-CT (Platelet Function Analyzer Closure Times) above 300 seconds. VWD type $1 \mathrm{~m}$ heterozygous Y1584/WT mutant in the A2 domain have prolonged PFA-CT ranging from the upper limit of normal to 300 seconds. Three of seven cases of Y1584C/WT mutants type 2 using the VWF:RCo/VWF:Ag ratio changed into type 1 using the VWF:GPIbM/VWF:Ag and VWF:GPIbR/VWF:Ag ratios (Table 6). Double heterozygous Y1584/G39R and A2Y1584C/P812rfs missense/null mutations are associated with severe VWD 
type 1 (Table 6).

Table 4. Results in VWD $2 A$ in 16 affected members from 5 families with the G1579R mutation in the A2 domain and the G1609R mutation in the A2 domain in one case of $V W D 2 A$.

\begin{tabular}{|c|c|c|c|c|c|c|c|c|c|c|}
\hline \multirow{2}{*}{ Mutation } & VWF:Ag & VWF:RCo & VWF:CB & GPIbM & GPIbR & RCo/Ag & GPIbM/Ag & VWFpp/ & ECLM & GPIbM \\
\hline & U/dL & U/dL & U/dL & $\mathbf{U} / \mathbf{d L}$ & U/dL & vs $\mathbf{C B} / \mathbf{A g}$ & GPIbR/Ag & Ag ratio & diagnosis & GPIbR \\
\hline G1579R & 0.53 & 0.28 & 0.15 & 0.05 & 0.02 & 0.530 .28 & 0.100 .03 & 1.79 & $2 \mathrm{~A}$ & $2 \mathrm{~A}$ \\
\hline G1579R & 0.48 & 0.13 & 0.14 & 0.06 & 0.04 & 0.270 .29 & 0.130 .07 & 2.15 & $2 \mathrm{~A}$ & $2 \mathrm{~A}$ \\
\hline G1579R & 0.91 & 0.18 & 0.20 & 0.07 & 0.06 & 0.200 .22 & 0.070 .07 & 1.66 & $2 \mathrm{~A}$ & $2 \mathrm{~A}$ \\
\hline G1579R & 0.41 & 0.11 & 0.13 & 0.10 & 0.06 & 0.270 .33 & 0.240 .15 & 1.61 & $2 \mathrm{~A}$ & $2 \mathrm{~A}$ \\
\hline G1579R & 0.79 & 0.23 & 0.14 & 0.09 & 0.07 & 0.290 .18 & 0.110 .09 & 1.11 & $2 \mathrm{~A}$ & $2 \mathrm{~A}$ \\
\hline G1579R & 0.72 & 0.24 & 0.18 & 0.10 & 0.06 & 0.330 .24 & 0.140 .09 & 1.46 & $2 \mathrm{~A}$ & $2 \mathrm{~A}$ \\
\hline G1579R & 0.70 & 0.24 & 0.21 & 0.12 & 0.19 & 0.340 .31 & 0.170 .27 & 1.79 & $2 \mathrm{~A}$ & $2 \mathrm{~A}$ \\
\hline G1579R & 0.57 & 0.23 & 0.20 & 0.06 & 0.04 & 0.400 .35 & 0.110 .07 & 1.32 & $2 \mathrm{~A}$ & $2 \mathrm{~A}$ \\
\hline G1579R & 0.31 & 0.08 & 0.10 & 0.05 & zero & 0.260 .33 & 0.15 & 2.03 & $2 \mathrm{~A}$ & $2 \mathrm{~A}$ \\
\hline G1579R & 0.67 & 0.15 & 0.25 & 0.12 & 0.10 & 0.220 .38 & 0.180 .15 & 1.36 & $2 \mathrm{~A}$ & $2 \mathrm{~A}$ \\
\hline G1579R & 0.59 & 0.15 & 0.27 & $\mathrm{nt}$ & 0.03 & 0.250 .47 & nt 0.05 & 1.56 & $2 \mathrm{~A}$ & $2 \mathrm{~A}$ \\
\hline G1579R & 0.77 & 0.10 & 0.37 & 0.11 & 0.08 & 0.130 .49 & 0.14011 & 1.52 & $2 \mathrm{~A}$ & $2 \mathrm{~A}$ \\
\hline G1579R & 0.44 & 0.10 & 0.11 & zero & 0.03 & 0.230 .24 & nt 0.06 & 1.52 & $2 \mathrm{~A}$ & $2 \mathrm{~A}$ \\
\hline G1579R & 0.42 & 0.14 & 0.12 & 0.05 & 0.02 & 0.330 .29 & 0.100 .03 & 1.69 & $2 \mathrm{~A}$ & $2 \mathrm{~A}$ \\
\hline G1579R & 0.48 & 0.05 & 0.20 & 0.05 & 0.03 & $0.100,41$ & 0.100 .07 & 1.35 & $2 \mathrm{~A}$ & $2 \mathrm{~A}$ \\
\hline G1579R & 0.95 & 0.06 & 0.26 & 0.16 & 0.19 & $0,060.28$ & 0.170 .20 & 1.46 & $2 \mathrm{~A}$ & $2 \mathrm{~A}$ \\
\hline G1579R/ & 0.84 & 0.04 & 0.14 & 0.04 & 0.20 & & & & $2 \mathrm{~A}$ & $2 \mathrm{~A}$ \\
\hline G1609R & 0.46 & 0.09 & 0.14 & 0.04 & 0.04 & 0.200 .31 & 0.130 .23 & 1.30 & $2 \mathrm{~A}$ & $2 \mathrm{~A}$ \\
\hline
\end{tabular}

Table 5. Summary Results from the Brno cohort of VWD $2 A$ patients with the G1579R mutation in the A2 domain in sixteen affected members from five families and in one case with the G1609R mutation in the A2 domain.

\begin{tabular}{|c|c|c|c|c|c|c|c|c|c|}
\hline Mutation & VWF:Ag & VWF:RCo & VWF:CB & GPIbM & GPIbR & $\mathrm{RCo} / \mathrm{Ag}$ & GPIbM/Ag & VWFpp/ & ECLM \\
\hline G1579R & U/dL & $\mathrm{U} / \mathrm{dL}$ & $\mathrm{U} / \mathrm{dL}$ & U/dL & $\mathrm{U} / \mathrm{dL}$ & vs $\mathbf{C B} / \mathbf{A g}$ & GPIbR/Ag & Ag ratio & GPIbM/ R \\
\hline Range & $0.41-0.95$ & $0.04-0.28$ & $0.11-0.37$ & $0.04-0.12$ & $0.03-0.20$ & $0.06-0.53$ & $0.03-0.27$ & $1.11-2.15$ & $2 \mathrm{~A}$ \\
\hline G1609R & 0.46 & 0.09 & 0.14 & 0.04 & 0.04 & 0.200 .31 & 0.130 .23 & 1.30 & $2 \mathrm{~A}$ \\
\hline
\end{tabular}
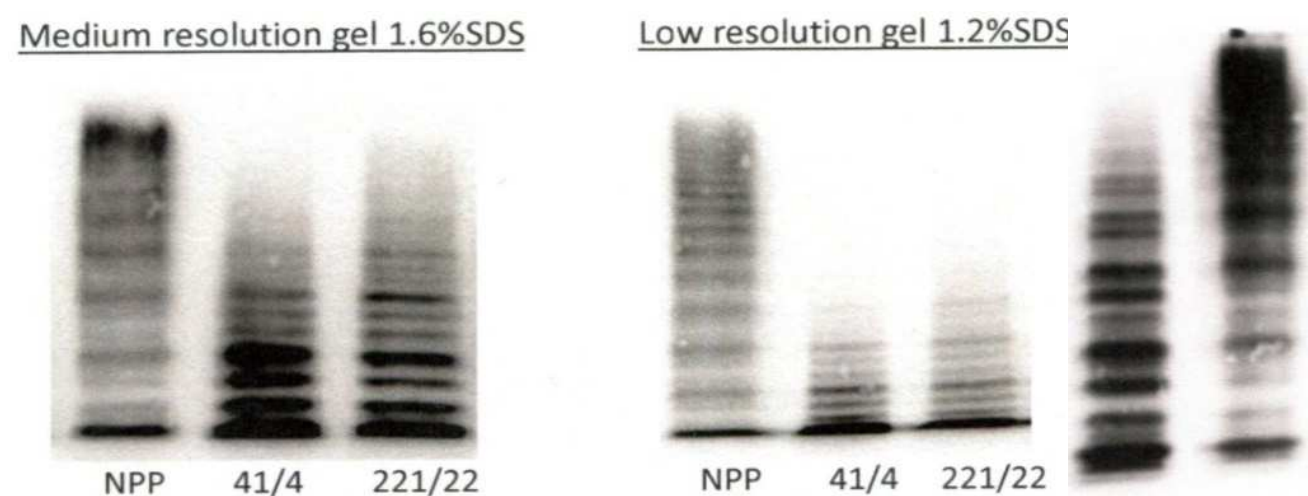

Figure 3. Left and middle set. Von Willebrand factor (VWF) multimeric analysis in SDS gel electrophoresis (left NPP, 41/4 and 221/22) as compared to normal platelet poor plasma (NPP) in medium resolutation gel $1.6 \%$ SDS and low resolution gel $1.2 \%$ in a case of dominant VWD $2 \mathrm{~A}$ due to the mutation $\mathrm{R} 1579 \mathrm{~W}$ in the A2 domain (Table 4) showing the absence of large and intermediate VWF multimers and pronounced triplet structure of the remaining VWF bands. Right set. VWF multimer analysis in a medium and low resolution SDS gel from the proband of the Dutch family with VWD $2 B$ caused by the R1306W mutation (Table 6) showing the absence of large VWF multimers and pronounced triplet structure of the VWF bands.

Table 6. Results from the Brno cohort of VWD type 1 due to mutations in the A2 domain.

\begin{tabular}{|c|c|c|c|c|c|c|c|c|c|c|}
\hline Mutation & VWF:Ag & VWF:RCo & GPIbM/R & VWF:pp & RCo/Ag & GPIbM/R & VIII:C/ & ABO & PFA-CT & ECLM vs \\
\hline A2 Domain & U/dL & U/dl & U/dL & U/dL ratio & CB/Ag r & ratios & Ag ratio & & EPI ADP & GPIbM/R \\
\hline Y1584C/WT & 0.30 & 0.23 & 0.310 .33 & 0.571 .91 & 0.771 .10 & 1.031 .11 & 0.77 & $\mathrm{O}$ & 232206 & $1 \mathrm{~m} 1 \mathrm{~m}$ \\
\hline Y1584C/WT & 0.42 & 0.36 & 0.280 .33 & 0.700 .71 & 0.860 .71 & 0.660 .78 & 1.00 & $\mathrm{O}$ & 242192 & $1 \mathrm{~m} 1 \mathrm{~m}$ \\
\hline Y1584C/WT & 0.36 & 0.23 & 0.280 .30 & 0.591 .63 & $0.640,67$ & 0.790 .83 & 1.22 & $\mathrm{O}$ & 265249 & $2 / 1 \mathrm{~m} 1 \mathrm{~m}$ \\
\hline Y1584C/WT & 0.61 & 0.55 & 0.530 .59 & 0.540 .88 & 0.900 .77 & 0.870 .96 & 1.20 & A & 205148 & $1 \mathrm{~m} 1 \mathrm{~m}$ \\
\hline Y1584C/WT & 0.72 & 0.48 & 0.540 .68 & 0.610 .85 & 0.670 .68 & 0.740 .94 & 1.10 & A & $>300174$ & $2 / 1 \mathrm{~m} 1 \mathrm{~m}$ \\
\hline Y1584C/WT & 0.76 & 0.49 & 0.610 .61 & 0.680 .90 & 0.640 .92 & 0.800 .80 & 0.82 & A & $145 \mathrm{nt}$ & $2 / 1 \mathrm{~m} 1 \mathrm{~m}$ \\
\hline Y1584C/G39R & 0.12 & 0.09 & 0.130 .16 & 0.211 .77 & 0.751 .03 & 1.071 .31 & 1.63 & A & $>300>300$ & Severe 1SD \\
\hline Y1584C/G39R & 0.07 & 0.11 & 0.180 .29 & 0.243 .00 & 1.381 .49 & 2.193 .60 & 2.09 & A & $>300>300$ & Severe 1SD \\
\hline
\end{tabular}




\begin{tabular}{lllllllllll}
\hline Mutation & VWF:Ag & VWF:RCo & GPIbM/R & VWF:pp & RCo/Ag & GPIbM/R & VIII:C/ & ABO & PFA-CT & ECLM vs \\
\hline A2 Domain & U/dL & U/dl & U/dL & U/dL ratio & CB/Ag $\mathbf{~}$ & ratios & Ag ratio & EPI ADP & GPIbM/R \\
\hline Y1584C/P812rfs & 0.08 & 0.02 & nt 0.25 & $0.121,54$ & 0.251 .54 & nt 3.10 & 3.45 & O & $>300116$ & Severe 1 SD \\
\hline
\end{tabular}

VWD type $1 \mathrm{~m}$ heterozygous Y1584/WT mutant in the A2 domain have prolonged PFA-CT ranging from the upper limit of normal to 300 seconds. Three of seven cases of Y1584C/WT mutants changed from type 2 with decreased VWF:RCo/VWF:Ag ratios into type 1 with normal ratios for VWF:GPIbM/VWF:Ag and VWF:GPIbR/VWF:Ag. Double heterozygous Y1584/G39R and A2Y1584C/P812rfs missense/null mutations are associated with severe VWD type 1 secretion defect $(\mathrm{SD})$.

Table 7. Results from the Brno cohort in VWD 2B due to gain of function mutation in the Al domain.

\begin{tabular}{|c|c|c|c|c|c|c|c|c|c|c|}
\hline \multirow{2}{*}{ Mutation } & VWF:Ag & VWF:RCo & VWF:CB & GPIbM & GPIbR & RCo/Ag & GPIbM/Ag & VWFpp/ & ECLM & GPIbM/Ag ratio \\
\hline & $\mathrm{U} / \mathrm{dL}$ & $\mathrm{U} / \mathrm{dL}$ & $\mathrm{U} / \mathrm{dL}$ & $\mathrm{U} / \mathrm{dL}$ & $\mathrm{U} / \mathrm{dL}$ & vs $\mathbf{C B} / \mathbf{A g}$ & GPIbR/Ag & Ag ratio & diagnosis & GPIbR/Ag ratio \\
\hline R1306W & 0.54 & 0.38 & 0.43 & 0.20 & 0.08 & 0.700 .80 & 0.370 .14 & 2.36 & $2 \mathrm{~B} \mathrm{C}$ & $2 \mathrm{~B} \mathrm{C}$ \\
\hline R1306W & 0.43 & 0.19 & 0.26 & 0.12 & 0.08 & 0.440 .60 & 0.290 .30 & 3.08 & $2 \mathrm{~B} \mathrm{C}$ & $2 \mathrm{~B} \mathrm{C}$ \\
\hline R1306W & 0.27 & 0.04 & 0.12 & 0.05 & $\mathrm{nt}$ & 0.150 .44 & $0.15 \mathrm{nt}$ & 2.44 & $2 \mathrm{~B} \mathrm{C}$ & $2 \mathrm{~B} \mathrm{C}$ \\
\hline $\mathrm{R} 1308 \mathrm{C}$ & 0.26 & 0.12 & 0.09 & 0.08 & 0.03 & 0.460 .36 & 0.300 .09 & 2.54 & $2 \mathrm{~B} \mathrm{C}$ & $2 \mathrm{~B} \mathrm{C}$ \\
\hline R1308C & 0.29 & 0.06 & 0.11 & 0.06 & 0.02 & 0.210 .37 & 0.220 .06 & 2.69 & $2 \mathrm{~B} \mathrm{C}$ & $2 \mathrm{~B} \mathrm{C}$ \\
\hline R1341W & 0.42 & 0.37 & 0.27 & 0.20 & 0.14 & 0.880 .64 & 0.480 .34 & 1.49 & $2 \mathrm{~B}$ & $2 \mathrm{~B}$ \\
\hline $\mathrm{R} 1341 \mathrm{~W}$ & 0.62 & 0.23 & 0.25 & 0.21 & 0.26 & 0.370 .40 & 0.350 .42 & 0.85 & $2 \mathrm{~B}$ & $2 \mathrm{~B}$ \\
\hline Range & & $0.06-0.38$ & $0.11-0.43$ & $0.05-0.21$ & $0.03-0.14$ & & & & & \\
\hline
\end{tabular}

The ratios of VWF:RCo/VWF:Ag, VWF:CB/VWF:Ag, VWF:GPIbM/VWF:Ag and VWF:GPIbR/VWF:Ag are all decreased due to loss of large and some of the intermediate VWF multimers in VWD 2B patients with increased RIPA.

VWD 2B: gain of RIPA function mutation in the A1 domain

The values of VWF:GPIbM and VWF:GPIbR as compared to VWF:RCo and VWF:CB and its ratios in R1306W, R1308C and R1341W mutated cases of VWD 2B are significantly lower (Table 7). The higher sensitivity of the two novel rapid VWF:GPIbM and VWF:GPIbR assays as compared to the classical VWF:RCo assay in VWD $2 \mathrm{~B}$ is related to the absence of large and some of the intermediate VWF multimers (Figure 3). The ratios of VWF:RCo/Ag, VWF:CB/Ag, VWF:GPIbM/Ag and VWF:GPIbR/Ag are all decreased due to loss of large and some of the intermediate VWF multimers in VWD 2B. VWF multimeric analysis in a case of R1306W mutated VWD 2B patient showed the absence of large VWF multimers and a triplet structure of each VWF band in a medium resolution gel (Figure 3). In addition, elevated VWFpp/VWF:Ag ratios reveal clearance of VWF is increased the VWD 2B mutants R1306W and $\mathrm{R} 1308 \mathrm{C}$, but not in VWD 2B mutant R1341W. The unexpected finding is that in VWD $2 \mathrm{~B}$ the values for the novel rapid VWF:GPIbM and VWF:GPIbR activity assays and the VWF:GPIbM/Ag and VWF:GPIbR/Ag ratios in VWD $2 \mathrm{~B}$ are lower than the VWF:RCo/Ag and VWF:CB/Ag ratios (Table 7).

VWD 2M: loss of RIPA function mutation in Al domain

VWD $2 \mathrm{M}$ due to loss of RIPA function mutation in the A1 domain: E1359K mutated VWD 2M patients showed decreased VWF:Rco/VWF:Ag ratios and normal VWF:CB/VWF:Ag ratios as expected, whereas the values for the rapid VWF:GPIbR and VWF:GPIbM assays and the ratios for VWF:GPIbM/Ag and VWF:GPIbR/Ag ratios were decreased in a similar degree (0.14-.28), whereas the VWF:CB/VWF:Ag ratio is normal (Table 8). In VWD 2M the VWF:GPIbM/Ag ratio was somewhat higher (0.32-0.36) than VWF: $\mathrm{RCo} / \mathrm{Ag}$ ratio $(0.10-0.33)$ indicating the need to retain the VWF: $\mathrm{CB}$ assay to make a correct diagnosis of VWD 2M. Another unexpected finding is that G1415D mutated VWD $2 \mathrm{M}$ is featured by decreased RIPA and decreased VWF:RCo/Ag ratio but normal ratios for VWF:CB/Ag, VWF:GPIbM/Ag and VWF:GIbR/Ag and therefore to be diagnosed as VWD 1M (Table 8). Double heterozygous P1266L/V1278I mutation in two patients and heterozygous E1292D/WT mutation in three patients in the A1 domain were diagnosed as VWD 2M associated with a secretion defect (SD) or some increase of clearance (C) (Table 9). VWD 2M patients have decreased RIPA, normal ratio for $\mathrm{VWF}: \mathrm{CB} / \mathrm{Ag}$ ratios and decreased ratios for VWF:RCo/Ag, GPIbM/Ag and GPIbR/Ag indicating to retain RIPA and VWF:CB for the differentiation between VWD 2M and 2B. Mild cases of VWD 2M with decreased $\mathrm{VWF}$ ratio for $\mathrm{RCo} / \mathrm{Ag}$ ratios have near normal or normal VWF ratios for $\mathrm{CB} / \mathrm{Ag}$, GPIbM/Ag and GPIbR/Ag resulting in discrepancy of diagonosis either $2 \mathrm{M}$ or $1 \mathrm{M}$ (Tables 8,9$)$.

$V W D 2 M$ versus $1 m$ due to mutations in the A3 domain

Sevens patients double heterozygous for D1691E/WT or T1728S/WT mutations in the A3 domain and one case heterozygous for P2063S/WT mutation in the D4 domain had normal VWF RCo/VWF:Ag, VWF:GPIbR/VWF:Ag ratios and were diagnosed as VWD type $1 \mathrm{~m}$ (Table 10). Three heterozygous D1691E/WT cases had decreased ratios for FVIII:C/VWF:Ag ratio and normal VWF:CRo/VWF:Ag ratio consistent with VWD type 1 secretion defect. The values of all three functional VWF assays VWF:RCo, VWF:GPIbM and VWF:GPIbR assays in combination with the ratios of VWF:RCo/Ag, VWF:CB/Ag, VWF:GPIbM/Ag and VWF:GPIbR/Ag due to mutations in the D3 domain are consistent with VWD type $1 \mathrm{~m}$ or type $2 \mathrm{~m}$ (Table 10 ). 
Table 8. Results from the Brno cohort in VWD $2 M$ due to loss of function in the A1 domain.

\begin{tabular}{lllllllllll}
\hline \multirow{2}{*}{ Mutatie } & VWF:Ag & VWF:RCo & VWF:CB & GPIbM & GPIbR & RCo/Ag & GPIbM/Ag & VWFpp/ & ECLM & GPIbM/R ratio \\
\cline { 2 - 10 } & U/dL & U/dL & U/dL & U/dL & U/dL & vs CB/Ag & GPIbR/Ag & Ag ratio & diagnosis & on top of CB/Ag ratio \\
\hline E1359K & 1.36 & 0.30 & 1.27 & 0.46 & 0.25 & 0.220 .93 & 0.340 .18 & 0.93 & $2 \mathrm{M}$ \\
E1359K & 0.54 & 0.18 & 0.57 & 0.20 & 0.08 & 0.331 .05 & 0.360 .14 & 1.37 & $2 \mathrm{M}$ \\
E1359K & 0.73 & 0.07 & 0.77 & 0.25 & 0.19 & 0.101 .05 & 0.340 .26 & 1.25 & $2 \mathrm{M}$ & $2 \mathrm{M}$ \\
E1359K & 0.50 & 0.08 & 0.45 & 0.16 & 0.07 & 0.160 .89 & 0.320 .14 & 0.72 & $2 \mathrm{M}$ & $2 \mathrm{M}$ \\
E1359K & 0.89 & 0.08 & 0.53 & 0.31 & 0.25 & 0.160 .59 & 0.340 .28 & 1.24 & $2 \mathrm{M}$ \\
G1415D & 0.08 & 0.03 & 0.10 & 0.15 & 0.17 & 0.381 .22 & 1.902 .16 & 2.33 & $2 \mathrm{M} \mathrm{C}$ & $1 \mathrm{M} \mathrm{C}$ \\
G1415D & 0.19 & 0.06 & 0.15 & 0.16 & 0.31 & 0.320 .80 & 0.851 .62 & 1.81 & $2 \mathrm{M}$ & $1 \mathrm{M}$ \\
\hline
\end{tabular}

VWD 2M patients have decreased RIPA, normal VWF:CB/VWF:Ag ratios and decreased ratios for VWF:RCo/VWF:Ag, VWF:GPIbM and VWF:GPIbR indicating to retain RIPA and VWF:CB using collagen type I-III for the differentiation between VWD 2M and 2B.

Table 9. Results in mild VWD $2 M$ or $1 M$ due to mutations in the A1 domain.

\begin{tabular}{|c|c|c|c|c|c|c|c|c|c|c|}
\hline Mutation & VWF:Ag & VWF:RCo & GPIbM/R & VWF:pp & $\mathrm{RCo} / \mathrm{Ag}$ & GPIbM/R & VIII:C/ & ABO & PFA-CT & ECLM vs \\
\hline A1 Domain & $\mathbf{U} / \mathbf{d L}$ & U/dl & $\mathbf{U} / \mathbf{d L}$ & U/dL ratio & CB/Ag ratio & ratios & Ag ratio & & EPI ADP & GPIbM / R \\
\hline P1266L/V1278I & 0.25 & 0.13 & 0.250 .23 & 0.431 .70 & 0.520 .84 & 0.990 .91 & 2.36 & A & $>300237$ & $2 \mathrm{M} \mathrm{SD} 1 \mathrm{M}$ \\
\hline P1266L/V1278I & 0.45 & 0.33 & $\mathrm{nt}$ & 0.461 .02 & 0.520 .84 & $\mathrm{nt}$ & 1.36 & $\mathrm{O}$ & 215131 & $2 \mathrm{M} \mathrm{SD} n t$ \\
\hline E1292D/WT & 0.26 & 0.26 & 0.260 .86 & 0.311 .18 & 1.001 .00 & 0.861 .00 & 2.38 & $\mathrm{~B}$ & 211165 & $1 \mathrm{M} \mathrm{SD} 1 \mathrm{M}$ \\
\hline E1292D/WT & 0.46 & 0.16 & 0.260 .30 & 0.791 .72 & 0.350 .66 & 0.570 .66 & 1.11 & $\mathrm{O}$ & >300 297 & $2 \mathrm{M} 2 \mathrm{M}$ \\
\hline E1292D/WT & 0.35 & 0.13 & 0.250 .27 & 1.122 .00 & 0.370 .83 & 0.710 .71 & 1.26 & B & nt nt & $2 \mathrm{M} 1 \mathrm{M}$ \\
\hline
\end{tabular}

Mild cases of VWD 2M with decreased VWF:RCo/VWF:Ag and normal VWF:CB/VWF:Ag ratios (VWD 2M) but have near normal or normal valus for VWF:GPIbM and VWF GPIbR (VWD 1M).

Table 10. Results from the Brno cohort of mild VWD due to mutations in the A3 domain and in one case with a mutation in the D4 domain are mainly of Blood Group $O$ and diagnosed as VWD $1 \mathrm{~m}$ or $2 \mathrm{~m}$ with normal ratios for VWF:CB/VWF:Ag ratios.

\begin{tabular}{|c|c|c|c|c|c|c|c|c|c|c|}
\hline \multirow{2}{*}{ Mutation } & VWF:Ag & VWF:RCo & GPIbM/R & VWF:pp & RCo/Ag & GPIbM/R & VIII:C/ & ABO & PFA-CT & ECLM vs \\
\hline & $\mathrm{U} / \mathrm{dL}$ & U/dl & $\mathrm{U} / \mathrm{dL}$ & U/dL ratio & CB/Ag ratio & ratio & Ag ratio & & EPI ADP & GPIbM / R \\
\hline \multicolumn{11}{|l|}{ A3 Domain } \\
\hline D1691E/WT & 0.31 & 0.32 & 0.440 .43 & 0.551 .77 & 1.031 .39 & 1.431 .38 & 0.41 & $\mathrm{O}$ & 195167 & $1 \mathrm{~m}$ \\
\hline D1691E/WT & 0.63 & 0.65 & $0.520,64$ & 0.650 .80 & 0.780 .80 & $1.431,38$ & 0.59 & $\mathrm{O}$ & $\mathrm{nt} n t$ & $1 \mathrm{~m} 1$ \\
\hline D1691E/WT & 0.59 & 0.39 & 0.520 .63 & 0.701 .19 & 0.661 .09 & 0.640 .80 & 0.68 & $\mathrm{O}$ & nt nt & 2 or $1 \mathrm{~m} 2$ or 1 \\
\hline T1728S/WT & 0.98 & 0.63 & 0.880 .90 & 1.051 .08 & 0.640 .82 & 0.890 .92 & 1.29 & $\mathrm{O}$ & 214164 & 2 or $1 \mathrm{~m} 1$ \\
\hline V1706I/WT & 0.55 & 0.47 & 0.450 .42 & 0.510 .93 & 0.851 .11 & 0.820 .77 & 1.11 & A & $153 \mathrm{nt}$ & $1 \mathrm{~m} 1$ \\
\hline V1706I/WT & 0.61 & 0.69 & 0.620 .59 & 0.570 .93 & 1.131 .20 & 1.020 .96 & 1.36 & $\mathrm{O}$ & $137 \mathrm{nt}$ & $1 \mathrm{~m} 1$ \\
\hline \multicolumn{11}{|l|}{ D4 Domain } \\
\hline P2063S/WT & 0.57 & 0.53 & 0.530 .51 & 0.591 .03 & 0.930 .79 & 1.151 .13 & 1.19 & $\mathrm{O}$ & $146 \mathrm{nt}$ & $1 \mathrm{~m} 1$ \\
\hline
\end{tabular}

Platelet Function Analyzer Closure Times (PFA-CTs).

The PFA-CTs derived from the large cohort of Brno VWD patients are strongly prolonged ( $>300$ seconds) in dominant VWD 2A, 2B, 2E and 2M (Dr Smejkal data on file 2019). The PFA-CTs in heterozygous C1584C/WT VWD type 1 patients were slightly prolonged with values between the upper limit of normal to 300 seconds. Double heterozygous Y1584/G39R and A2Y1584C/P812rfs mutations result in severe VWD type 1 secretion defect (SD) with strongly prolonged PFA-CTs $(>300 \mathrm{sec})$.

\section{Discussion in View of the Literture}

The present Brno VWF VWD study demonstrates the superiority of the novel rapid VWF assays in detecting VWD 2A, 2B and 2M similar as has been documented by Michiels et al in another recent report on the performance of rapid and classical assays in VWD 1, 2N and 2E [13]. In both studies we used a complete set of VWF assays for the diagnosis of
VWD according to 2018 ECLM criteria. Schneppenheim Michiels \& Budde demonstrated that the 22 VWD patients with different missense mutations in the D3 domain are mulitimerization defects and classified as VWD type 1E or 2E [14]. The recent study of Michiels, Smejkal \& Mayger in 2019 [13] showed that VWD type 1 due to a heterozygous mutation in the D1 domain is featured by a persistence of non-cleaved pro/mature/VWF as the cause of secretion and multimerization plus FVIII binding defect mimicking VWD type 3. VWD type 1 patient due to heterozygous/WT mutations in the D1 domain have decreased values for VWFpp and VWFpp/Ag ratios (0.51 to 0.99 with one exception) together with moderate to markedly prolonged PFA-CTs. VWD type 1E multimerization defect is frequently associated with an additional secretion defect (SD) with increased ratio for FVIII:C/VWF:Ag associated with the absence or presence of a clearance (C) defect with increased VWFpp/VWF:Ag ratio above 2.0) $[5,11,13]$. The ratios for VWF:RCo/VWF:Ag and the ratios VWF:GPIbR/VWF:Ag 
and VWF:GPIbM/VWF:Ag are variable either above or below the cut off level of 0.70 in VWD due to mutations in the D3 domain and therefore diagnosed as either type $1 \mathrm{E}$ or type $2 \mathrm{E}[11]$.

The present Brno study on the superiority of the novel rapid VWF activity assays in VWD 2A, 2B and 2M reveal both expected and novel observations. In dominant VWD 2A due to mutations in the A2 domain, the VWF:GPIbM/VWF:Ag and VWF:GPIbR/VWF:Ag ratios are markedly decreased in a similar degree as compared to VWF:RCo/VWF:Ag and VWF:CB/VWF:Ag ratios due to mutations in the A2 domain as the cause of proteolytic loss of large and intermediate VWF multimers as documented in Brno cohort of 17 VWD 2A patients caused by the G1579R mutation in sixteen cases and 1619 mutation in one case. Interestingly, no other mutations in the A2 domain as the cause of VWD 2A was observed in the large Brno cohort of 160 VWD patients. The present study shows that in dominant VWD 2B due to gain of RIPA function mutations R1306W, R1308C and R1341W in the A1 domain, the VWF:GPIbM/VWF:Ag and VWF:GPIbR/VWF:Ag ratios are more markedly decreased (range 0.09-0.42) as compared to VWF:RCo/VWF:Ag and VWF:CB/VWF:Ag ratios (range 0.40-0.64) due to the proteolytic loss of large and intermediate VWF multimers in VWD 2B. VWD 2M due to loss of RIPA function mutation in the A1 domain is featured by decreased VWF:RCo/VWF:Ag ratio and normal VWF:CB/VWF:Ag ratio, but the VWF:GPIbR/VWF:Ag ratio and the VWF:RCo/VWF:Ag ratio are similar low whereas the ratio of VWF:GPIbM/VWF:Ag was somewhat higher or even normal indicating the need to retain the VWF:CB assay to make a correct diagnosis of VWD 2M [11]. The VWD 2M mutation $\mathrm{R} 1359 \mathrm{~K} / \mathrm{WT}$ due loss of RIPA function mutation in the A1 domain is featured by normal VWF:CB/VWF:Ag ratio (range 0.80-1.05), decreased VWF:RCo/VWF:Ag ratio (range 0.100.38 ) and decreased VWF:GPIbR/VWF:Ag ratio (range 0.1428) but the VWF:GPIbM/VWF:Ag ratio was somewhat higher (range 0.32 to 0.36 ) again indicating the need to retain the VWF: CB and RIPA assay for the diagnostic differentiation between VWD 2M and VWD 2B. Interestingly, loss of RIPA function mutation G1415D/WT in the A1 domain is featured by decreased RIPA and VWF:RCo/VWF:Ag ratio (VWD 2M) but normal ratios for VWF:CB/Ag, VWF:GPIbM/Ag and GPIbR/Ag consistent with VWD 1M. Mild VWD due to double heterozygous P1266L/V1278I mutation in two patients and heterozygous E1292D/WT mutation in three patients in the A1 domain were diagnosed as VWD $2 \mathrm{M}$ or $1 \mathrm{M}$ associated with a secretion defect (SD). The Brno cohort of VWD patients did not contain other variants of loss of RIPA function muations in the A1 domain and only contained one mutation in the D4 domain and none in the C1-C6 and CK domains. The majority of VWF mutations in the D4 and $\mathrm{C} 1$ to $\mathrm{C} 6$ reported in the literature are VWD type $1 \mathrm{SD}$ with smeary $(1 \mathrm{sm})$ or normal $(1 \mathrm{~m})$ multimers with no or a minor clearance defect except for the heterozygous S2179F mutation in the D4 domain featured by VWD type 1 secretion and clearance (SCD) $[11,13]$. The large Brno cohort of VWD patients showed that the PFA-CTs are strongly prolonged $(>300 \mathrm{sec})$ in ECLM defined recessives VWD type 1 and $2 \mathrm{C}$ due to homozygous or double heterozygous mutation in the $\mathrm{D} 1$ and $\mathrm{D} 2$ domains, and in ECLM defined dominant $2 \mathrm{~A}, 2 \mathrm{~B}, 2 \mathrm{E}$ and $2 \mathrm{M}$ due to heterozygous mutations in the D3, A1 and A2 domains (Table 2) $[11,13]$. PFA-CTs are moderately prolonged in ECLM defined mild VWD type 1 patients due to heterozygous mutations in the D1, D2, D', A3, D4 and C1-C6 domains and in some mutations located in the A1 (P1266L) and A2 (Y1584C) domains. PFA-CTs are slightly prolonged in LowVWF carriers of a null or missense mutation ranging from 0,30 and 0,50 U/dL. The 2019 study of Michiels Smejkal \& Mayger showed that PFA-CT is normal or near normal in LowVWF patients with VWF values between 0.40 to 0.70 $\mathrm{U} / \mathrm{dL}$ with the absence of a causative mutation in the VWF gene [13].

Based on expert experiences in VWD and our analyses of the Brno VWD cohort in two previous studies [8, 9], Michiels, Smejkal \& Mayger directly compared in this report the rapid VWF:GPIbM and VWF:GPIbR assays against a complete set of classical VWF assays in view of the performances of rapid VWF: GPIbM vs classicalVWF:RCo assays in the Dutch Nijmegen study [15] and the results of the direct comparison of VWF:GPIbM, VWF:GPIbR and VWF:RCo assays in the French study [16]. The Laboratory of Hematology Thrombosis and Hemostasis Unit, University Medical Center (UMC), Nijmegen compared the ristocetin independent functional VWF:GP1bM (INNOVANCE) activity assay with the VWF:RCo assay (Van Duren et al BARI Congres 2013, Figure 4) [15] in type 1 and 2 VWD patients classified according to ISTH criteria confirmed by genotype. The Dutch Nijmegen included 44 genetically confirmed ISTH defined VWD patients: type $1 \mathrm{~N}=9$, type $2 \mathrm{~A}$ (IIA and IIE) $\mathrm{N}=9$, type $2 \mathrm{~B} \mathrm{~N}=6$, type $2 \mathrm{M} \mathrm{N}=9$, type $2 \mathrm{~N} \mathrm{~N}=6$, type $1 / 2 \mathrm{~N} \mathrm{~N}=4$, type $3 \mathrm{~N}=1$ acquired VWF syndrome (AVWS) $\mathrm{N}=1$ and 12 non VWD patients directly comparing VWF:GP1bM versus VWF:RCo. The overall slope between VWF:RCo vs VWF:GP1bM was $1.26=0.09$ (Figure 4) indicating that the VWF:GP1bM showed overall lower VWF levels compared to VWF:RCo and 23 samples (23\%) were at least $20 \%$ higher in the VWF:GP1bM assay as compared to VWF:RCo (data not shown). As illustrated in Figure 4, the VWF:GP1bM/VWF:Ag ratios were around 1.0 in non-VWD and in $2 \mathrm{~N}$ VWD patients. The ratios for VWF:GP1bM/Ag were below 0.70 in 2 and above 0.70 in 7 of 9 VWD type 1 patients. The ratios for VWF:GP1bM/Ag were around 0.40 (range 0.25-0.60) in nine VWD 2B patients, which can be explained by the lack of large VWF multimers in VWD 2B. The ratios for VWF:GP1bM/RCo showed a broad range (0.50-1.00) in ISTH defined VWD type 2A (IIA and IIE) (Figure 4). The ratios for VWF:GPIbM/RCo are increased between 1.0 and 1.8 in VWD $2 \mathrm{M}$ and very low ratios around 0.50 in clasical VWD 2B (Figure 4). The important observation in the Dutch Nijmegen ISTH defined VWD study is that VWF:GP1bM values are significantly lower compared to the VWF:RCo assays in VWD 2B patients, which can be ascribed to the lack of the large and some of the intermediate VWF multimers in VWD 2B (Figure 3) due to 
gain of RIPA function mutations in the A1 domain. In contrast, the VWF:GPIbM values are significantly higher or even normal as compared to VWF:RCo values in VWD 2M patients, which can readily be explained by the various degrees of some loss or the presence of large VWF multimiers in VWD $2 \mathrm{M}$ due to loss of RIPA function mutations in the A1 domain.

The French VWD study of De Maitre et al evaluated and compared the performance of two newly commercialized assays VWF:GPIbM (INNOVANCE) and VWF:GPIbR (VWF:RCo Acustar) against classical VWF:Ag and VWF:RCo in a cross sectional study of 123 pathological samples of VWD patients classified according to the ISTH classification in Figure 5 [16]. The mean values and standard deviations of the classical VWF:Ag, VWF:RCo versus the rapid VWF:GPIbR and VWF:GPIbM assay measurements in 22 ISTH defined Type 1, 15 type 2A (lumping IIA and IIE), 13 type $2 \mathrm{~B}$ and 3 type $2 \mathrm{U}$ and in 47 ISTH defined LowVWF patients in the study of De Maitre et al are informative and show characteristic findings for each of the VWD subtypes [16]. The VWF:Act/Ag ratios are normal (above 0.70) in VWD type 1, in LowVWF and controls showed normal ratios for VWF:RCo/Ag, VWF:GPIbR/Ag and VWF:GPIbM/Ag (Figure 5). These data of the French VWD study clearly show that the sensitivity and specificity of each of the functional VWF assays VWF:RCo, VWF:GPIbR and VWF:GPIbM are accurate and not different for the diagnosis of VWD type 1 and LowVWF as compared to controls. This has been confirmed in 2018 and 2019 by Vangenechten et al in the large Brno cohort of VWD type 1 patients [8, 9]. In contrast, the analysis of the performances of the three VWF assays VWF:RCo, VWF:GPIbR and VWF:GPIbM in ISTH defined IIA, IIE, 2B, $2 \mathrm{M}$ and $2 \mathrm{U}$ VWD patients subdivided into ECLM defined VWD 2A, 2B, 2E, 2B, 2M and 2U show significant differences similar as observed by Michiels et al in the this report (Tables 4 to 10) and in a recent Brno study [13]. The VWF ratios for GPIbM/Ag, GPIbR/Ag and GPIbM/Ag were similar and most pronounced decreased and the lowest (range 0.20-0.50) in all ISTH defined IIA and ECLMP 2A defined VWD $(\mathrm{N}=6)$ due to the loss of large VWF multimers caused by mutations in the A2 domain. The VWF;GPIbM/Ag, VWF:GPIbR/Ag and VWF:GPIbM/Ag ratios were similar in ISTH defined IIE $=$ ECLM $2 \mathrm{E}$ defined VWD showing mean values around 0.70, range 0.50-1.60. These data of the French VWD study nicely confirm the findings in 2018 and 2019 by Vangenechten et al in ISTH defined 2A (lumping IIA and IIE = ECLM 2A and 2E) VWD patients of the large Brno cohort [8, 9]. The VWF:GPIbM/Ag ratio was most pronouncedly decreased (range $0.20-0.50$ ) in 12 of 13 VWD 2B (compared to decreased VWF:GPIbR/Ag ratio in 9 of $12 \mathrm{VWD} 2 \mathrm{~B}$ and decreased ratio of $\mathrm{VWF} ; \mathrm{RCo} / \mathrm{Ag}$ in 8 of $12 \mathrm{VWD} 2 \mathrm{~B}$ (Figure 5).VWD $2 \mathrm{~B}$ is featured by loss of large VWF multimers caused by gain of RIPA function mutations in the A1 domain. This important finding has been confirmed in the German (Table 2), Dutch Nijmegen (Figure 4) and the Brno (Table 6) cohorts of VWD 2B patients.
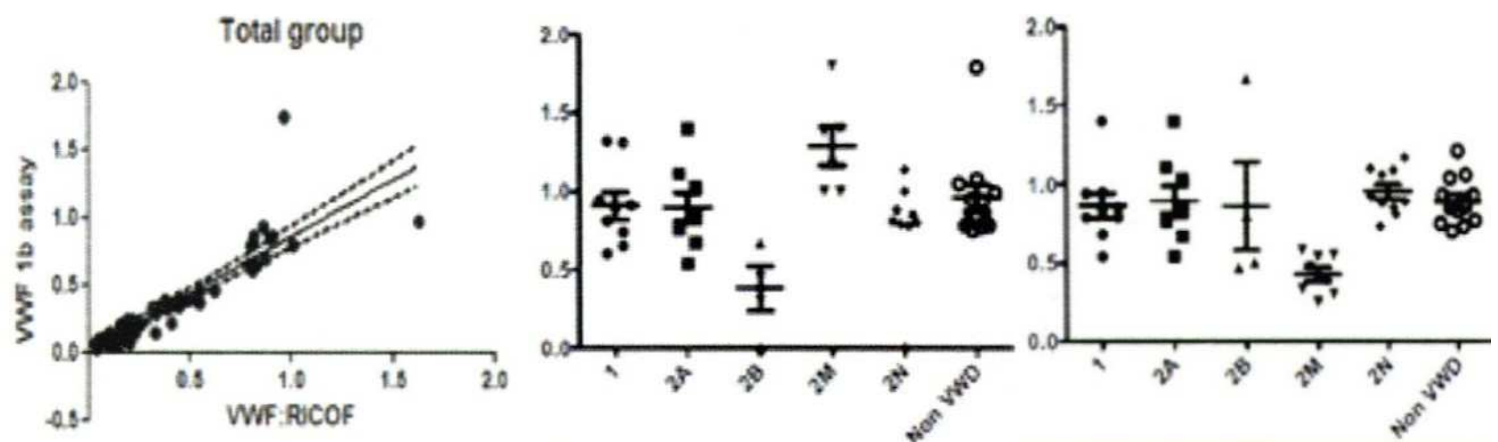

Figure 4. Results of the Dutch Nijmegen Study [26]. Left: Direct comparison of VWF:RCo versus VWF:GPIbM (VWF 1b assay). The overall slope between $V W F: R C o(U / d L)$ versus VWF:GPIbM (VWF 1 b assay U/dL) in the Dutch Nijmegen study was 1.26 0.09 indicating that the VWF:GP1bM (INNOVANCE) assay showed overall lower VWF values at levels between zero to $0.50 \mathrm{U} / \mathrm{dL}$ as compared to VWF:RCo values (2 outlier values). Middle: VWF:GPIbM/VWF:Ag ratios in VWD type 1, 2A (IIA and IIE), 2B, 2M, 2N patients and Non-VWD individuals. The VWF:GP1bM/VWF:Ag ratios were around 1.0 in Non-VWD and in $2 N$ VWD patients. The VWF:GP1bM/VWF:Ag ratios in nine VWD type 1 patients were above 0.70 in 7 and below 0.70 in 2 patients. The VWF:GP1bM/VWF:Ag ratios in nine VWD $2 A$ patients were around 0.90 and (range 0.50 to 1.00 and two around1.30) can only be explained that the ISTH defined VWD $2 A$ is a mixture of IIA (2A) and IIE (2E), See Figure 4 French VWD study. The VWF GPIbM/VWF:Ag ratios in six VWD 2B were significantly lower with values below 0.5 and mean values around 0.25 in VWD $2 B$ due to the loos of large VWF multimers. (See Table 8). The $V W F: G P 1 b M / V W F: A g$ ratios were normal (range 0.7-1.4) in non-VWD and $2 N$ VWD patients. Right: Functional VWF RCo/VWF:GIbM ratios in VWD type 1, $2 A, 2 B, 2 M, 2 N$ and Non-VWD individuals. The functional VWF:RCo/VWF:GPIbM ratios were normal in non-VWD and $2 N$ and showed a broad range from 0.60 to 1.5 in VWD type 1,VWD $2 A$ and VWD $2 B$ showing a broad range but was decreased below 0.60 in VWD $2 M$ indicating that the combined use of $V W F: A g, V W F: R C o$ and $V W F: C B$ are needed to distinguish VWD $2 M$ with the presence of large VWF multimers.

The ratios of VWF:GPIbM/VWF:Ag were the lowest (less than 0.40 , range $0.10-0,60$ ) in VWD 2B due to gain of RIPA function mutations in the A1 domain in the VWF gene as demonstrated in the four German [10, 11] Brno [8, 9], Nijmegen [15] and French [16] cohort studies of VWD patients. In contrast, the VWF:GPIbM/VWF:Ag ratios are higher usually above 0.40 or even normal (range 0.40 to 1.5 ) VWD 2M due to loss of RIPA function mutations in the A1 domain of the VWF gene indicating the need for combined use of VWF:Ag, VWF:RCo or VWF:GPIbR, RIPA and 
VWF:CB assays are needed to distinguish VWD 2M from VWD 2B and 2A. The VWF:GPIbM values are much lower than the VWF:RCo values and the VWF:GPIbM/RCo ratio is around 0.50 in VWD type $2 \mathrm{~B}$ (Figure 4 right) similar as seen in the German INNOVANCE study (Table 2) [11], the Brno $[8,9]$ and French study (Figure 5) [16] indicating that the VWF:GPIbM assay as compared to both VWF:RCo and VWF: GPIbR assays is more sensitive to the loss of large and some of the intermediate VWF multimers in VWD 2B. The overall findings of VWF activity/antigen ratios using the three methods VWF:RCo, VWF:GPIbR and VWF:GPIbM assays were comparable in VWD type $1(n=22)$, low VWF $(n=47)$ and controls $(n=11)$ (Figure 5) [16]. Separation of ISTH defined VWD 2A $(n=15)$ in the French study into IIA $(n=9)$ and IIE $(n=6)$ clearly show very low VWF Act/Ag ratios of 0.20 to 0.50 for ISTH defined VWD IIA in three functional assays VWF:RCo, VWF:GPIbR and VWF:GPIbM, but the ratios ranged from about 0.60 to 1.00 in ISTH defined VWD IIE in the three functional assays VWF:RCo, VWF:GPIbR and VWF:GPIbM. The findings in the German [10, 11], Dutch Nijmegen [15] and French [16] VWD studies were similar as the findings in the large Brno VWD studies analysed in 2018/2019 by Vangenechten et al [8, 9, 11, 13].

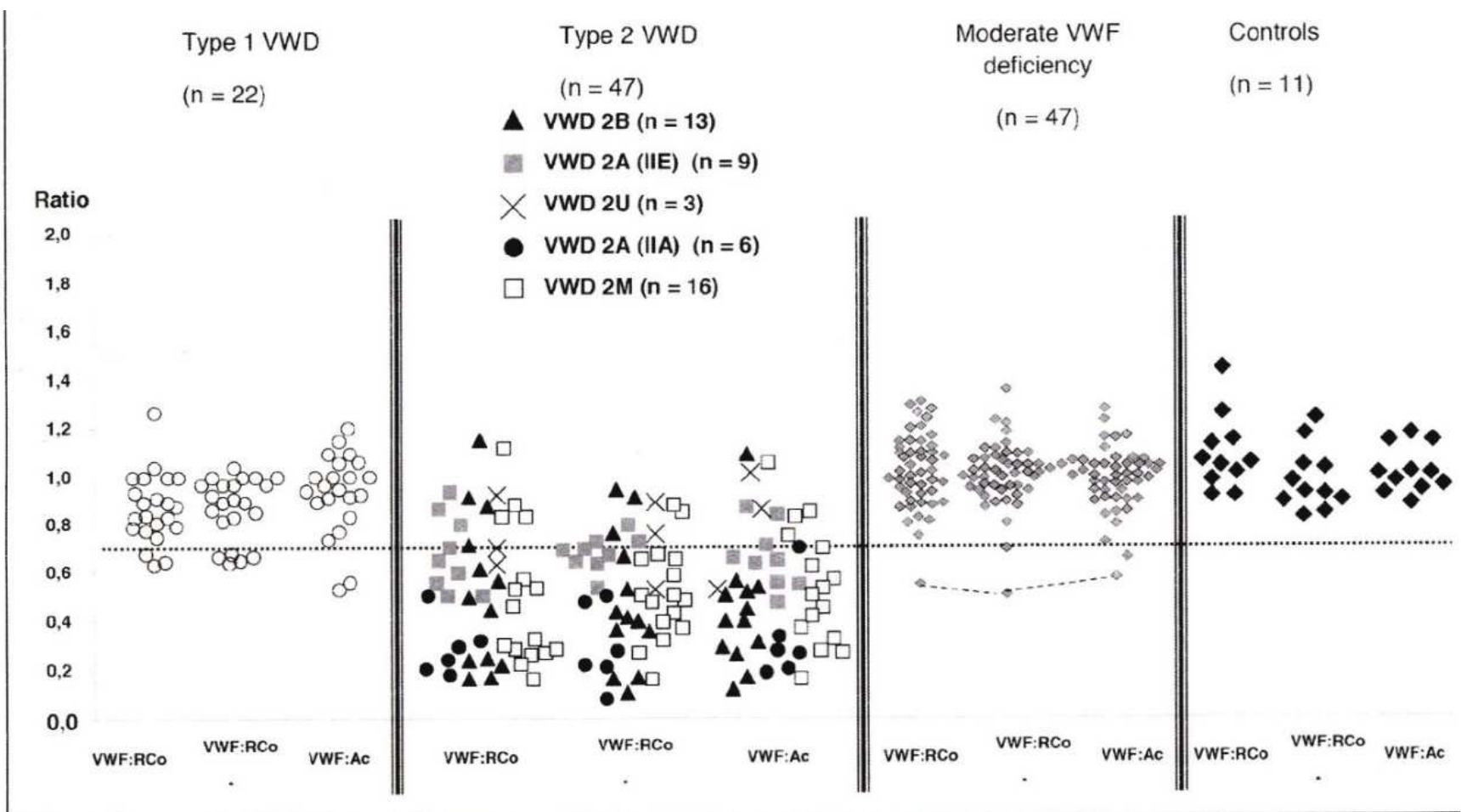

\begin{tabular}{llllllll}
\hline & $\begin{array}{l}\text { Type 1 } \\
\mathbf{n = 2 2}\end{array}$ & $\begin{array}{l}\text { Type 2A } \\
\mathbf{n = 1 5}\end{array}$ & $\begin{array}{l}\text { Type 2B } \\
\mathbf{n = 1 3}\end{array}$ & $\begin{array}{l}\text { Type 2M } \\
\mathbf{n = 1 6}\end{array}$ & $\begin{array}{l}\text { Type 2U } \\
\mathbf{n = 3}\end{array}$ & $\begin{array}{l}\text { Type 3 } \\
\mathbf{n = 6}\end{array}$ & $\begin{array}{l}\text { Moderate deficiency } \\
\mathbf{n = 4 7}\end{array}$ \\
\hline WWF:Ag & $26.4 \pm 7.5$ & $36.7 \pm 23.2$ & $44.7 \pm 15.6$ & $26.1 \pm 12.5$ & $21.7 \pm 13.1$ & $<1$ & $50.6 \pm 10.5$ \\
WWF:RC0 & $21.8 \pm 6.5$ & $18.3 \pm 13.7$ & $24.3 \pm 17.1$ & $12.2 \pm 8.1$ & $17.3 \pm 13.1$ & $<5$ & $48.8 \pm 10.8$ \\
WWF:RCo-Acu & $22.5 \pm 7.7$ & $17.2 \pm 11.1$ & $21.8 \pm 14.3$ & $12.9 \pm 7.5$ & $16.3 \pm 11.2$ & $<0.5$ & $48.2 \pm 11.8$ \\
WWF:AC & $23.5 \pm 7.4$ & $16.6 \pm 9.0$ & $18.6 \pm 10.4$ & $14.0 \pm 10.0$ & $16.0 \pm 12.5$ & $<5$ & $47.2 \pm 10.4$ \\
\hline
\end{tabular}

Figure 5. Results of the French study (27). Laboratory results of patients with VWD type 1, left versus ISTH defined type 2 VWD $2 B, 2 A$ (IIE), 2U, 2A (IIA) and $2 M$ versus LowVWF and controls in the French study (upper part) [27]. The table and figure reveal that ISTH defined VWD type 1 patients had VWF levels below $0.30 \mathrm{U} / \mathrm{L}$ and LowVWF patients above $0.30 \mathrm{U} / \mathrm{L}$.

The VWF Act/Ag ratios in the French VWD study were above 0.70 in twenty-two ISTH defined type 1 VWD patients for the three functional VWF acyivity assays VWF:GPIbM, VWF:GPIbR and VWF:RCo. The VWF Act/Ag ratios in ISTH defined 9 cases of VWD IIE were below 0.70 for the VWF: $\mathrm{RCo} / \mathrm{Ag}$ ratio in 5 cases, equal to in 4 cases or below 0.70 in 4 cases for VWF:GPIbR/Ag ratio and below 0.70 in 6 of 8 cases for VWF:GPIbM/Ag ratio (Figure 5). All LowVWF patients had normal VWF Act/Ag ratios for all three VWF functional activity assays VWF:GPIbM/Ag,
VWF:GPIbR/Ag and VWF: RCo/Ag except 2 cases.

ISTH defined type 2 VWD patients in the French study were confirmed by genotype [27]. The values in the table of VWF:RCo, VWF:GPIbR and VWF:GPIbM are comparative in VWD 2A (IIA) and 2M, whereas in VWD 2B the values for VWF:GPIbM were lower than for VWF:RCo with values for VWF:GPIbR in between. In ISTH defined type 2 VWD the VWF Act/Ag ratio of all three VWF activity assays was below 0.70 in 6 of 6 IIA (2A); 6 of 9 IIE (2E); 9 of 13 2B; 12 of $162 \mathrm{M}$; and 1 of $32 \mathrm{U}$ patients. The VWF Act/Ag ratio was 
above 0.70 in 3 of $13 \mathrm{VWD} 2 \mathrm{~B}$ cases for the VWF:RCo/Ag and VWF:GPIbR/Ag assays. The VWF/Ag ratio above 0.70 in only 1 of 13 VWD 2B cases for VWF: GPIbM/Ag. The VWF Act/Ag ratio was above 0.60 in 5,8 and 6 of nine VWD IIE patients for VWF:RCo/Ag, VWF:GPIbR/Ag and VWF:GPIbM/Ag assays respectively. The VWF Act/Ag ratio was below 0.60 for all three VWF activity assays in all 6 IIA (2A) VWD patients with one exception for the VWF:GPIbM/Ag assay. Such discrepant findings are in urgent need for critical evaluation in large scale prospective international multicenter studies in well defined VWD patients using a complete set of FVIII:C and VWF assays.

\section{Contribution of the Authors}

AG, PS, JJM, ZB and MP founded in 2008 the AntwerpBrno collaboration on VWF-VWD Research. KM and GM, JB and UB joined in 2013 the Brno Antwerp VWF-VWD project as an activity within the ISTH. JJM, PS, KM and AG initiated the study and wrote the manuscript. KM, GM, IV and OZ performed the VWF laboratory investigations. JJM and PS translated the ISTH into the ECLM classification of VWD. JB, MP, UB andZB served as senior scientific consutant

\section{References}

[1] Michiels JJ, Berneman Z, Gadisseur A, van der Planken M, Schroyens W, van de Velde A, van Vliet HHDM. Classification and characterization of hereditary types 2A, 2B, 2C, 2D, $2 \mathrm{E}, 2 \mathrm{M}, 2 \mathrm{~N}$ and $2 \mathrm{U}$ (Unclassifiable) von Willebrand disease. Clin Applied Thromb Hemostas 2006; 12 (4): 397420 .

[2] Michiels JJ, van Vliet HHDM, Berneman Z, Gadisseur A, van der Planken M, Schroyens W, van de Velde A, Budde U. Intravenous DDAVP and FVIII-von Willebrand factor concentrate for the treatment and prophylaxis of bleedings in patients with von Willebrand disease type 1,2 and 3. Clin Applied Thromb Hemostas 2007; 13 (1): 14-34.

[3] Michiels JJ, Berneman Z, Gadisseur A, van der Planken M, Schroyens W, van Vliet HHDM. Laboratory diagnosis and molecular basis of mild von Willebrand disease type 1. Acta Haematol 2009; 121: 85-97.

[4] Gadisseur A, Berneman Z, Schroyens W, Michiels JJ. Pseudohemophilia of Erik von Willebrand caused by homozygous one nucleotide deletion in exon 18 of the VWfactor gene World J Hematol 2013; 6; 2 (4): 99-108.

[5] Gadisseur A, Hermans C, Berneman Z, Schroyens W, Declmyn H, Michiels JJ. Laboratory diagnosis and molecular classification of von Willebrand disease. Acta Haematol 2009; 121: 71-84.

[6] Michiels JJ, Batorova A, Pricangova T, Smejkal P, Penka M, Vangenechten I, Gadisseur A. Changing insights in the diagnosis and classification of recessive and dominant von
Willebrand diseases. World J Hematol 2016; 5 (3): 61-74. Doi: 10.5315/wjh.v5i.3.61.

[7] Michiels JJ, Smejkal P, Penka M, Batorova A, Pricangova T, Budde U, Vangenechten I, Gadisseur A. Diagnostic differentiation of von Willebrand disease type 1 and 2 by von Willebrand factor multimer analysis and DDAVP challenge test Clin Applied Thromb Hemostas 2017; 23 (6): 518-531.

[8] Vangenechten I, Mayger K, Smejkal P, Zapletal O, Michiels JJ, Moore GW, Gadisseur A. A comparative analysis of different automated von Willebrand factor glycoprotein Ibbinding activity assays in well typed von Willebrand disease patients. J Thromb Haemostas 2018; 16: 1-10 https://doi.org/10.1111/jth.14145.

[9] Vangenechten I, Smejkal P, Zapletal O, Michiels JJ, Berneman Z, ZavrelovaJ, Blatny J, Penka M, Gadisseur A. Analysis of von Willebrand Disease in the South Moravian population (Czech Republic): Results from the BRNO-VWD Study. Thromb Haemostas 2019; 119: 594-605.

[10] Patzke J, Budde U, Huber A, Mendez A, Muth H, Obser T, Peerschke E, Wilkins M, Schneppenheim R. Performance evaluation and multicentre study of a von Willebrand factor activity assay based on GLIb binding in the absence of ristocetin. Blood Coag Fibrinolys 2014; 25: 860-870.

[11] Michiels JJ, Smejkal P, Zapletal O, Penka M, Blatny J, Budde U, Mayger K, Moore GW, Vangenechten I, Gadisseur A. Determination of two rapid von Willebrand factor (VWF) activity assays VWF: GPIbM and VWF: GPIbR in welldefined von Willebrand disease patients using a complete set of classical and sensitive VWF assays J Hemtol Thromb Dis 2019, 6: 5 DOI 10.417/2329-8790.100029.

[12] Van den Heuvel E, de Laat B, Eckman CM, Michiels JJ, van Mourik J, Versteegh FGA. A novel type 2A von Willebrand factor mutation (V1499E) associated with variable clinical expression. J Pediatr Hematol Oncol 2009; 31 (4): 277-280.

[13] Michiels JJ, Smejkal P, Mayger K, Moore G, Budde U, Berneman Z, Vangenechten I, Gadisseur A, Blatny J, Penka M. Combined use of rapid von Willebrand factor (VWF) activity, VWF-propetide and classical VWF assays for improved diagnosis of von Willebrand disease type $1,2 \mathrm{~N}$ and $2 \mathrm{E}$ due to mutations in the D1, D2, D', D3 and D4 domains of the VWF gene. Thromb Hemostas Res 2019; 3 (2) 1027.

[14] Schneppenheim R, Michiels JJ, Obser T et al. A cluster of mutations in the D3 domain of von Willebrand factor correlates with a distinct subgroup of von Willebrand disease type 2A/2 E. Blood 2010; 115 (23): 4894-4901.

[15] Van Duren C, Schoormans S, Brons P, Laros-Gorkom BAP, van Heerde WL. Determination of the VWF activity with the ristocetin independent gain of function Glycoprotein $1 \mathrm{~b}$ Innovance von Willebrand Activity Assay. Poster-BARI International Conference WWW.bic2014org/posters.

[16] Maitre E, Volot F, Mourey G, Aho LS, Ternisien C, Briquel ME, Bertrand MA, Tardy B, Frotscher B, Nguyen P, Dumont L, Vandroux D, Hezard N, Trossart M. Performance of two new automated assays for measuring von Willebrand activity: HemosIL AcuStarand Innovance. Thromb Haemostas 2014; 112 DOI.org/10.1160/TH14-02-0108. 